\title{
Ambulatory extracorporeal membrane oxygenation (ECMO) as a bridge to lung transplantation
}

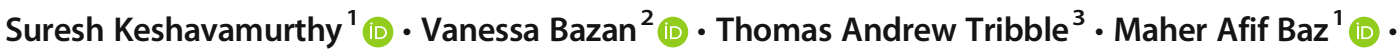 \\ Joseph Bertram Zwischenberger ${ }^{1}$
}

Received: 1 March 2021 / Revised: 29 April 2021 / Accepted: 2 May 2021 / Published online: 1 September 2021

(C) Indian Association of Cardiovascular-Thoracic Surgeons 2021

\begin{abstract}
Ambulatory extracorporeal membrane oxygenation (ECMO) has shown promise as a bridge to lung transplantation. The primary goal of ambulatory ECMO is to provide enough gas exchange to allow patients to participate in preoperative physical therapy. Various strategies of ambulatory ECMO are utilized depending upon patients' need. A wide spectrum of ECMO configurations is available to tackle this situation. We discuss those configurations in this article.
\end{abstract}

Keywords Ambulatory ECMO · Bridge to lung transplantation $\cdot$ VV ECMO $\cdot$ VA ECMO

\section{Introduction}

Extracorporeal life support (ECLS) provides temporary cardiopulmonary support for critically ill patients who fail to respond to conventional treatment and are expected to recover in days to weeks or after receiving definitive therapy [1]. ECLS has been used as a successful bridge to lung transplantation in appropriately selected patients who have acutely decompensated and are either waiting to be listed or are listed and awaiting transplantation [2].

The technique of bridging with extracorporeal membrane oxygenation (ECMO) is relatively recent. In fact, up until 10 years ago, ECMO was considered a contraindication to lung transplant due to potential complications of a prolonged ECMO course including hemolysis, bleeding, stroke, infection, and renal insufficiency [3]. Technical advances, management improvements, availability of different devices, and

Suresh Keshavamurthy

suresh.keshavamurthy@uky.edu

1 Department of Surgery, Division of Cardiothoracic Surgery, University of Kentucky College of Medicine, 740 S. Limestone, A-301, Lexington, KY 40536, USA

2 University of Kentucky College of Medicine, William R. Willard Medical Education Building, MN 150, Lexington, KY 40536, USA

3 Mechanical Circulatory Support Coordinator, MCS Department, Gill Heart \& Vascular Institute, 1000 S. Limestone Pav A.08.273, Lexington, KY 40536, USA improved outcomes demonstrated by the Conventional Ventilation or ECMO for Severe Adult Respiratory Failure (CESAR) trial and the ECMO to Rescue Lung Injury in Severe Adult Respiratory Distress Syndrome (ARDS) (EOLIA) trial for adults with respiratory distress syndrome resulted in the surge of ECMO bridging for lung transplantation [4-7]. Since 2005, the use of ECMO as a bridge to transplant (BTT) has increased significantly. Recently, approximately $5 \%$ of patients are bridged to lung transplant using ECMO compared to $1 \%$ in $2005(p<0.001)$ [8].

\section{ECLS configurations}

The term extracorporeal life support is an umbrella term that is used to describe all variations of ECMO. Veno-venous ECMO (VV ECMO), used for respiratory support, drains blood from and returns blood to venous circulation. Venoarterial ECMO (VA ECMO), used for both respiratory and cardiac support, drains blood from venous circulation and returns it to arterial circulation (Fig. 1).

The best options for acute respiratory failure are VV ECMO circuits with either one or two vascular access sites [9]. Two-site vascular access can be achieved by percutaneously cannulating the internal jugular vein (IJ) and femoral vein (fem) or bilateral femoral veins. The IJ-fem and Femfem configurations can both be done at the bedside and can be done expeditiously. Patients with femoral catheters are conventionally not ambulated due to the risk of bleeding and 
Fig. 1 Ambulatory ECMO decision guide VV-Veno-Veno; VA-Veno-Arterial; ECCO2R, extracorporeal carbon dioxide removal; RA, right atrium; PA, pulmonary artery; Ax-A, axillary artery; VA-V, veno-arterialvenous; RV, right ventricle; oxy RVAD, oxygenator in right ventricular assist device circuit; ECLS, extracorporeal life support

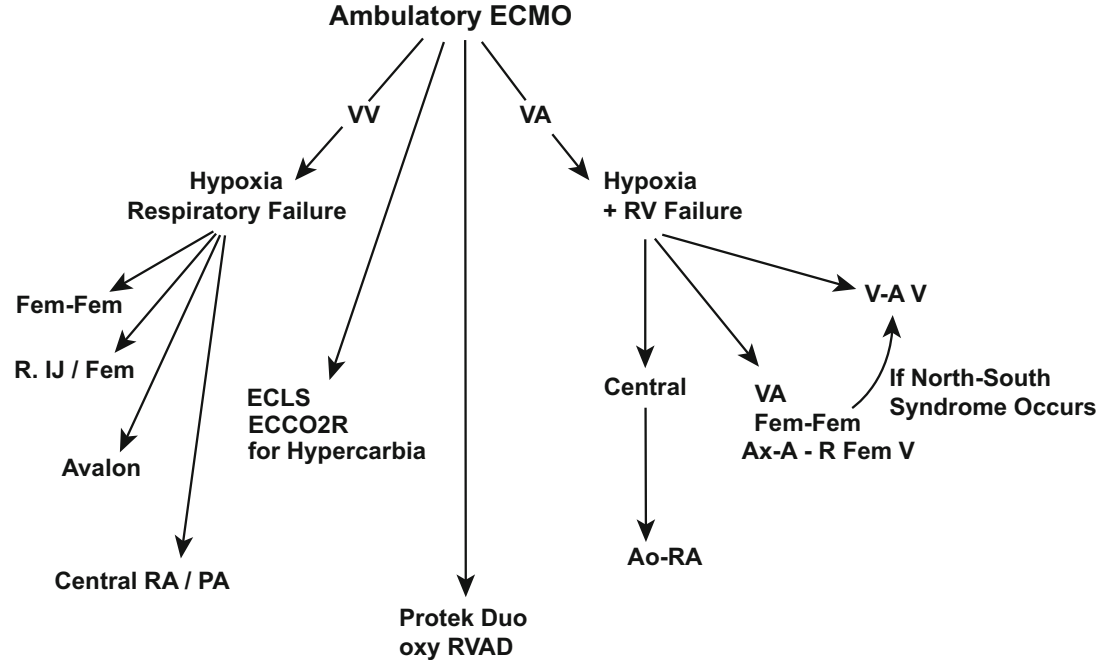

displacement, however current practices are evolving. A case series by Pasrija et al. [10] demonstrated success ambulating select VA ECMO patients with an arterial catheter in the femoral artery. Patients walked a median of $300 \mathrm{ft}(91.44 \mathrm{~m})$ on days they ambulated. There were no major bleeding events, vascular complications, or decannulation events. All 15 ambulated patients survived for 1 year. Similarly, Shudo et al. reported their experience with an ambulatory bridge to heartlung transplantation using femoral VA ECMO. [11] If the patient is stable enough for non-emergent cannulation, the preferred VV ECMO configuration is with a single vascular access site in the IJ using a dual-lumen cannula (DLC) [12]. At our institution, we prefer to intubate the patient before cannulating for ECMO in order to have more control during the procedure. Extubation is planned after the successful procedure.

\section{Ambulatory ECMO}

\section{VV ECMO}

\section{Right internal jugular vein/left IJ/right femoral vein/left femoral vein}

VV ECMO using the right internal jugular vein (RIJ)-right femoral vein (RFV) configuration is the first choice especially when being instituted in an urgent setting (Fig. 2a). This can be accomplished at the bedside in the intensive care unit (ICU) using ultrasound guidance and is quick and expeditious. The rationale for using the RFV for the drainage cannula is that the RFV has a relatively straighter course compared to the left and can be technically difficult. Our preference is to use a 24-F Edwards Lifescience Femoral Venous Cannula REF\#VFEM024 or 25-F Edwards Lifescience QuickDraw Venous Cannula Ref\# QD25 for and an 18-F Edwards
Lifescience Femoral Arterial Cannula Ref\# FEMII018A or 20-F Edwards Lifescience Femoral Arterial Cannula Ref\# FEMII020A for the return in the RIJ.

\section{VV ECMO Fem-fem (right for return and left for drainage)}

While using the fem-fem configuration we use a 24 or $25 \mathrm{~F}$ size drainage cannula (Fig. 2b); however, we place that in the left femoral vein (LFV) and position it around the 35-40 cm mark to avoid recirculation. The return cannula is a Medtronic Bio-medicus 19F ref.\# 96670-019 cannula.

Fem-Fem needs planning and proper cannulae and optimum placement in order to be successful; the common cause of failure/recirculation is improper cannula choice and positioning. Fluoroscopy/C-arm might be helpful if difficulty is encountered in negotiating the cannula due to space constraints in the inferior vena cava (IVC).

While easier to institute, both these configurations suffer from a mobility standpoint. Also, if the RIJ-RFV or Fem-fem cannulae are in close proximity, there is a risk of recirculation. The color of blood in the drainage cannula should normally be dark and one should suspect recirculation if it appears brighter red or shows intermittent streaks. Our approach is to review the pre-oxygenator, post-oxygenator, and patient blood gases daily in addition to X-rays.

Decreased patient $\mathrm{pO} 2$ due to hypoxia and increased saturation in the drainage cannula, usually greater than or equal to $80 \%$, should also raise the suspicion for recirculation.

Here are a set of blood gases which illustrate the phenomenon of recirculation:

Pre ECMO blood gas: pH 7.37/pCO2 $42 \mathrm{mmHg} / \mathrm{pO} 2$ $46 \mathrm{mmHg} / \mathrm{O} 2$ saturation $80 \%$

Post ECMO blood gas: pH 7.41/ pCO2 36 mmHg/ pO2 $374 \mathrm{mmHg} / \mathrm{O} 2$ saturation $100 \%$ 
Fig. 2 a Showing RIJ-RFV VV ECMO cannula configuration; right internal jugular vein (RIJ) (return) and right femoral vein (RFV) (drainage). b Showing Fem-fem VV ECMO cannula configuration; RFV (right femoral vein) (return) and LFV (left femoral vein) (drainage)

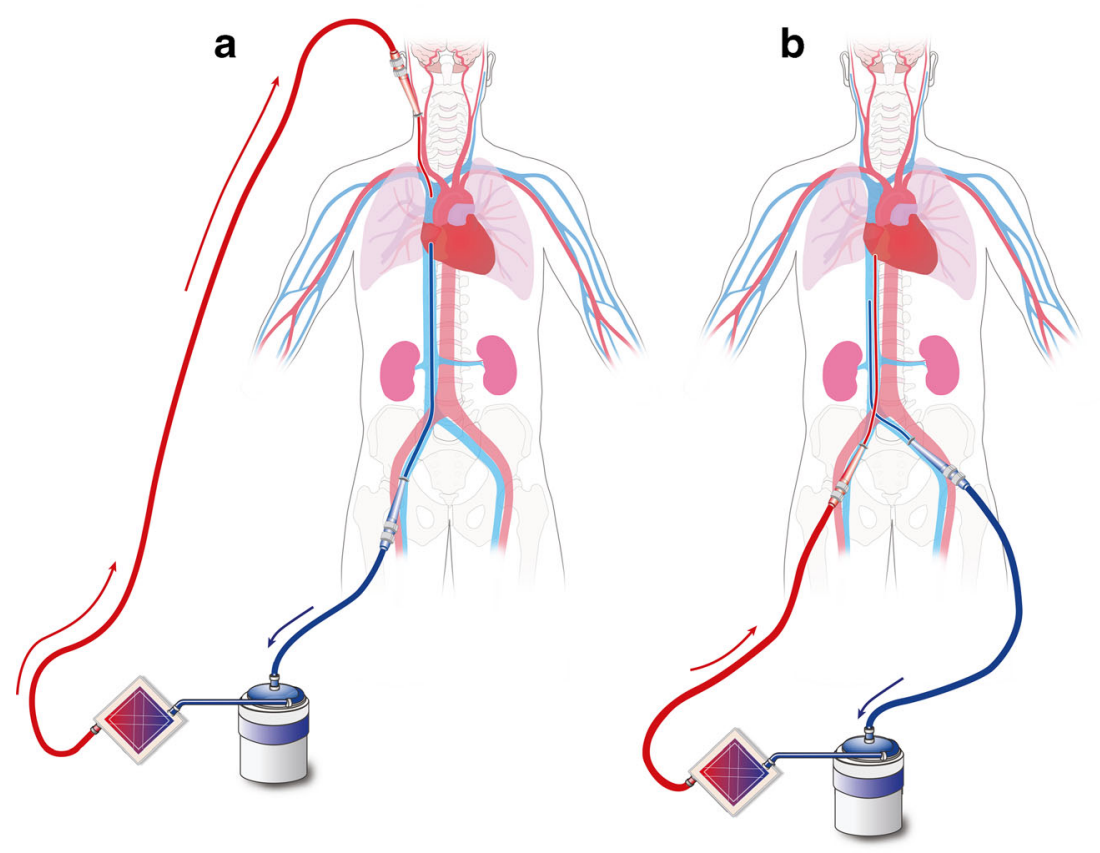

While it is possible to have a separation of $10-14 \mathrm{~cm}$ for the RIJ-RFV configuration, this is more difficult to achieve for the Fem-fem arrangement. Therefore, it is of utmost importance to choose the appropriate cannula type when going for the Fem-fem arrangement; the drainage cannula should be the larger diameter multi-hole cannula whereas the return cannula preferably inserted in the RFV is the smaller end-hole cannula; this minimizes the chance of recirculation. The return cannula should be inserted till it can be pushed no more while the drainage cannula is generally positioned above the renal veins or in the hepatic IVC.

$\mathrm{CO}_{2}$ clearance can also be assessed by analyzing the blood gases. A failing oxygenator may display $\mathrm{CO}_{2}$ retention requiring increases in sweep gas flows. Moreover, if the post membrane pO2 is less than 200, an oxygenator change might be warranted. To be emphasized, however, the pre/post membrane gases only reflect the membrane performance and not the patient's overall clinical picture.

\section{VV ECMO DLC}

a) Bicaval: Dual-lumen VVECMO using the Avalon Elite ${ }^{\mathrm{TM}}$ or Crescent $\AA$ cannula with single-site access via the RIJ or left subclavian vein with a DLC, can achieve total gas exchange pre-transplantation for native lung deterioration and post-transplant for early graft failure [12]. All available DLCs are placed either via the right IJ or left subclavian vein and can be grossly categorized by where the catheter tip is placed within the central venous system. Bicaval DLCs (Avalon and Crescent) traverse the superior vena cava (SVC), right atrium (RA), and IVC. Bicaval
DLCs include the Avalon Elite (Maquet, Rastatt, Germany) and the Crescent (Medtronic, MN).

b) Unicaval DLCs terminate in the SVC/right atrial junction and available catheters include the OriGen DLC (Origen Biomedical, Austin, TX) and Novaport Twin (Xenios, Heilbronn, Germany).

The advantages of dual-lumen veno-veno ECMO (dlVV ECMO) include ease of participation in physical therapy, increased ambulation potential, and improved patient comfort if able to extubate. It avoids groin access required by the Fem-fem cannulation strategy thereby decreasing the chance of line contamination and increasing the opportunity for participating in physical therapy and ambulation. Early mobility reduces the length of ICU/hospital stay and improves functional outcomes at discharge [13]. Sedation cessation also encourages physical therapy, early mobilization, and rehabilitation and is demonstrated to benefit ECMO patients awaiting lung transplantation [14-16]. Our institution uses an algorithm for mobilization to guide patient ambulation decisions (Figs. 3 and 4) $[17,18]$.

Potential disadvantages of dl-VV ECMO include the need for image-guided insertion (although ultrasound-guided insertion is possible) and the risk of displacement or perforation if improperly inserted [19]. Possible complications of insertion include tachyarrhythmia's from guidewire migration into the right ventricle, guidewire coiling when using a floppy wire, and perforation while using a stiff wire. Right ventricle perforation with the guidewire and tamponade is a potentially lethal complication if undetected. Suboptimal position or 


\section{ECMO MOBILITY SCREENING}

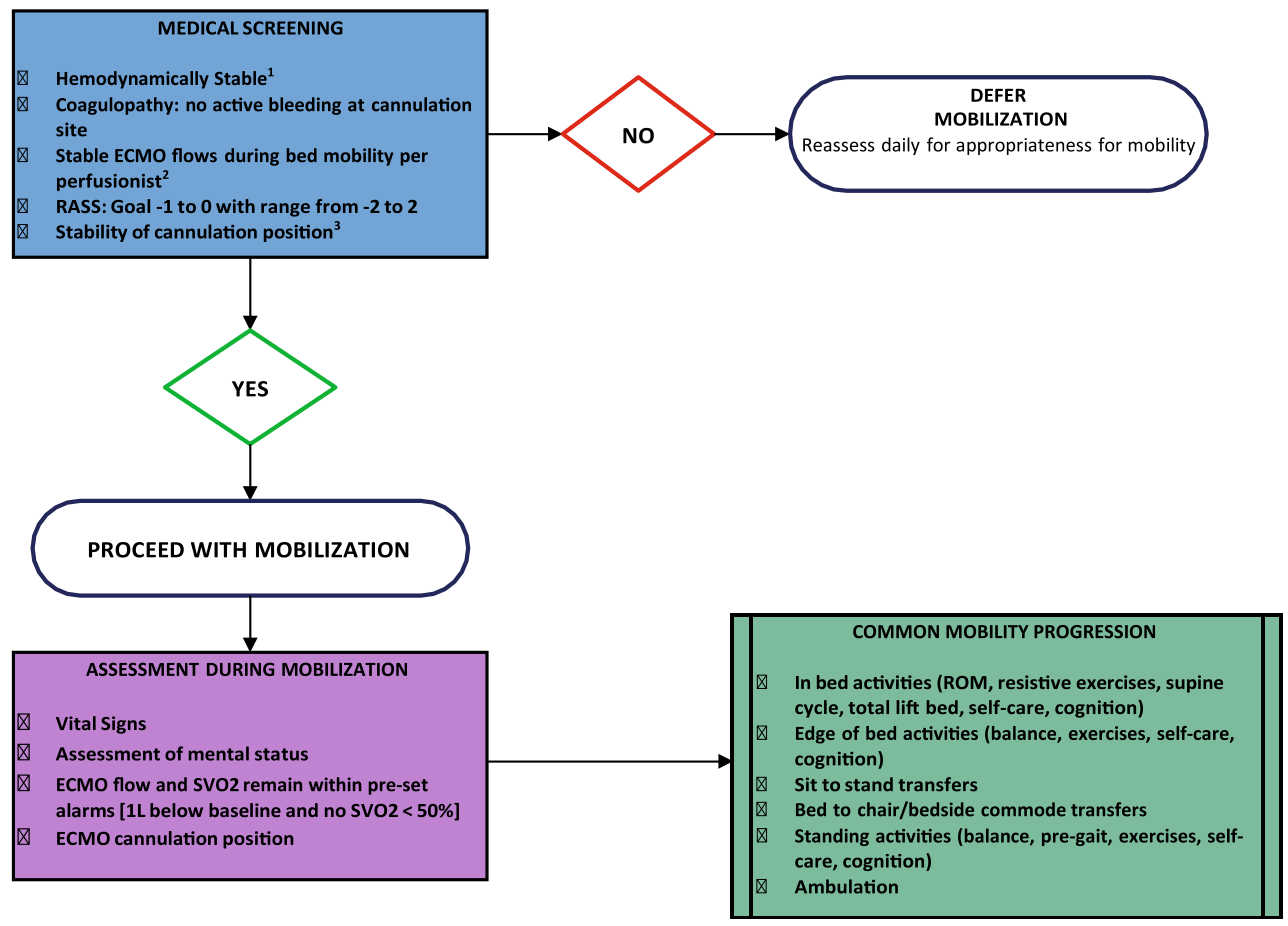

Fig. 3 ECMO mobility screening. Adapted with permission from Wells CL, Forrester J, Vogel J, Rector R, Tabatabai A, Herr D. Safety and feasibility of early physical therapy for patients on extracorporeal membrane oxygenator: University of Maryland Medical Center experience. Crit Care Med. 2018;46(1):53-59 [17]. (1) No resting heart rate (HR) equal to age-predicted MAX HR, no third-degree heart block, no sustained VT, no A-Fib with RVR with unstable pressure, and no significant changes within the past $2 \mathrm{~h}$, or as determined by medical team

malposition while ambulating may lead to significant recirculation, exacerbating hypoxia, and hemolysis (Fig. 5). We prefer to confirm the cannula position with daily chest X-rays and assume optimum positioning if there is a wide arterio-venous (AV) difference; the pre-oxygenated samples having low pO2 (30-40 $\mathrm{mmHg}$ ) and low saturations (less than 60-70\%) compared to high pO2 (generally greater than $300 \mathrm{mmHg}$ ) and high saturations (100\%) in the post-oxygenator sample and adequate respiratory support. Intracranial hemorrhage is a dreaded complication of all modalities of ECMO. Insertion of a large-bore cannula into the IJ can possibly increase cerebral venous pressure promoting hemorrhage. A review of the extracorporeal life support organization (ELSO) registry (2011-2016) comparing propensity-matched VV ECMO patients cannulated with the Avalon Elite $27 \mathrm{Fr}$. $(n=372)$ or 31 Fr. $(n=372)$ found the rate of intracranial hemorrhage was 3 times higher in those cannulated with the larger catheter $(n=$ $16,4.3 \%$ v. $n=6,1.6 \%, p=0.03$ ). These results suggest the use of the smallest cannula able to achieve adequate ECMO flow to minimize the risk of intracranial hemorrhage [20]. However, the limitation of the smaller cannula is that it might and physician order. (2) No drop-in flow >1 L with flexion of hip to 90 degrees for $10 \mathrm{~s}$. (3) Cannulae must be secured with an external device (Foley strap, abdominal binder) and junctions reinforced with zip-ties. Abbreviations: RASS, Richmond Agitation-Sedation Scale; SVO2, mixed venous oxygen saturation; ROM, range of motion; A-Fib, atrial fibrillation; RVR, rapid ventricular response; VT, ventricular tachycardia; max HR, maximum heart rate

not be able to provide enough flow if the patient's clinical condition deteriorates.

Inhaled epoprostenol (iEPO) could be a cost-effective alternative to inhaled nitric oxide (iNO); however, close monitoring must be kept on methemoglobinemia [21-23].

Tachycardia is treated with B-blockade to decrease native cardiac output and thereby decrease shunting.

VV ECMO with either two cannulae (IJ-Fem or Fem-Fem) dual-site access or dual-lumen and single cannula (IJ) single site access are the best options for acute respiratory failure. If no plans to initiate ECMO had been in place, emergent percutaneous cannulation at the bedside via the IJ and femoral vein or femoral-femoral veins may be required.

The DLC traverses the SVC, RA, with the tip placed in the IVC. Venous drainage ports positioned in the SVC and IVC draw blood to supply the oxygenator. After the gas exchange, the blood is returned to the infusion lumen of the catheter, terminating at a port directed towards the tricuspid valve (TV).

The downside of $(\mathrm{dl}) \mathrm{VV}$ is the need for image-guided insertion, and the risk of displacement or perforation, if improperly inserted [19]. 
Fig. 4 Adapted with permission from Hodgson CL, Stiller K, Needham DM, et al. Expert consensus and recommendations on safety criteria for active mobilization of mechanically ventilated critically ill adults. Crit Care. 2014;18(6):658. DOI: https://doi.org/10.1186/s13054014-0658-y [18]. Abbreviations: EVD, extra ventricular drain; LD, lumbar drain; ICP, intracranial pressure; RASS, Richmond agitation-sedation scale; FiO2, fraction of inspired oxygen; PEEP, positive end-expiratory pressure; $\mathrm{O}_{2}$ oxygen; MAP, mean arterial pressure; CRRT, continuous renal replacement therapy

\section{GUIDELINE FOR OUT OF BED MOBILIZATION OF THE MECHANICALLY VENTILATED PATIENT ${ }^{1}$}

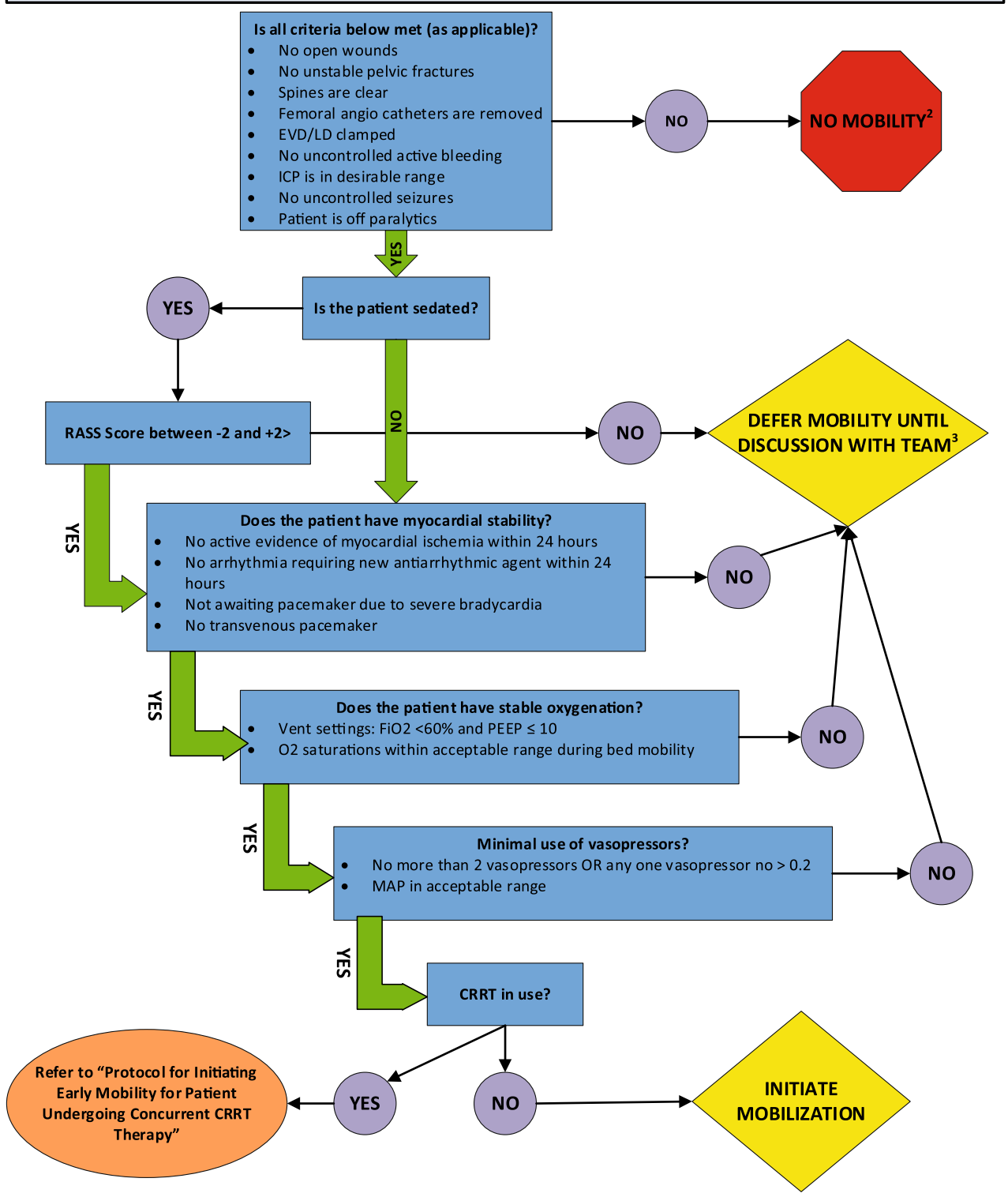

In cases of worsening cardiac dysfunction while on VV ECMO, hemodynamic support can be achieved with the addition of an infusion cannula to the subclavian artery or femoral artery, while converting the VV ECMO circuit to a venoarterial-venous (hybrid VAV) circuit [24]. If this can be done in an elective fashion, the addition of a subclavian cannula comes with the added advantage of mobility; however, if the need is urgent, a femoral arterial cannula serves the purpose.

The Avalon Elite DLC was introduced in 2009 and was quickly incorporated into the practice of adult ECMO (Fig. 6). Cannula size is based on patients' needs determined by body habitus, cardiac index (cardiac output divided by body surface area) and required blood flow for gas exchange. DLC sizes range from 13 to $31 \mathrm{Fr}$., with the smallest $13 \mathrm{Fr}$. cannulas used in neonates $>2.5 \mathrm{~kg}$. Adult sizes range from 20 to $31 \mathrm{Fr}$., with smaller 13 Fr.-19 Fr. sizes also available for small adults or children. The most common bicaval DLC sizes used in adult patients are 27-31 Fr. with larger cannulas capable of maintaining higher flow rates but associated with increased complications and bleeding at the cannulation site. [20] The Crescent $30 \mathrm{Fr}$. supports up to $7 \mathrm{~L} / \mathrm{min}$ of flow and the Avalon $27 \mathrm{Fr}$. supports up to $5 \mathrm{~L} / \mathrm{min}$ of flow. DLCs are especially suitable for hypercarbic respiratory failure. The smaller $19 \mathrm{Fr}$. Avalon supports up to $2.5 \mathrm{~L} / \mathrm{min}$ of flow. The unicaval NovaPort twin DLC used for extracorporeal carbon dioxide removal (ECCO2R) is optimized for lower flows with the $22 \mathrm{Fr}$. supporting up to $1.5 \mathrm{~L} / \mathrm{min}$ and the $18 \mathrm{Fr}$. supporting up to $1.0 \mathrm{~L} / \mathrm{min}$ of flow. Lower flow rates readily accomplish $\mathrm{CO}_{2}$ removal, but most surgeons prefer full gas exchange support when bridging patients to lung transplantation. 


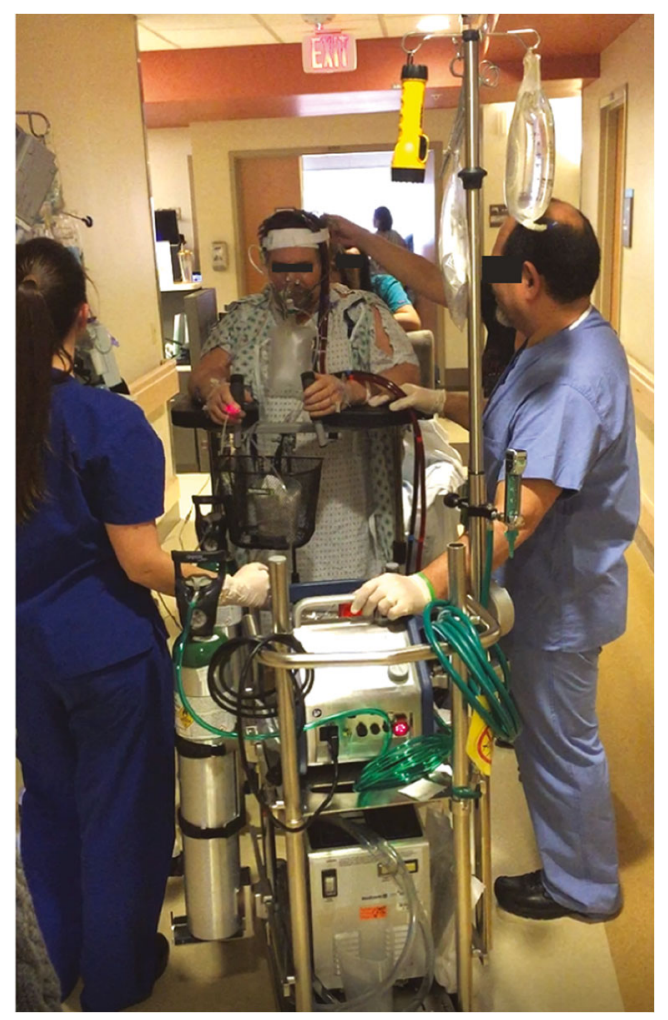

Fig. 5 Ambulatory ECLS; patient ambulating with an indwelling DLC

\section{Surgical techniques}

Fluoroscopy and transthoracic echocardiography (TTE) at bedside or trans esophageal echocardiography (TEE) in the operating room (OR) should visualize the guidewire traverse the SVC, RA, and IVC and confirm placement beyond the level of the renal veins prior to cannulation [25]. Visualization of the guidewire in the SVC and IVC does not exclude looping within the RA/right ventricle [26]. A singlecenter chart review of 72 patients cannulated with the Avalon Elite DLC reported 2 cases of cardiac perforation during insertion despite the use of fluoroscopic guidance [27].

We recommend the use of a purse-string suture at the insertion site with 2/0 silk. We then use no.1 Ethibond to secure the DLC at multiple sites to the skin. Specifically, the suture is placed through the skin and a knot made with a couple of snugs, but not tight, throws such that the skin is not cinched; this suture is then used to go around the cannula with a secure knot.

Close to the hub, there is a groove for the suture; however, we prefer to anchor at multiple places to avoid migration and dislodgement especially for ambulation. This is repeated every $3-5 \mathrm{~cm}$ for both cannula limbs. To allow for patient comfort and stabilization of the ECMO lines, a 30-in. Hold-nPlace Foley Leg Band should be placed across the patient's forehead and lines secured by the green Velcro strap [28].

After successful insertion, the position is confirmed by an $\mathrm{X}$-ray chest and abdomen and the cannula tip should be at the

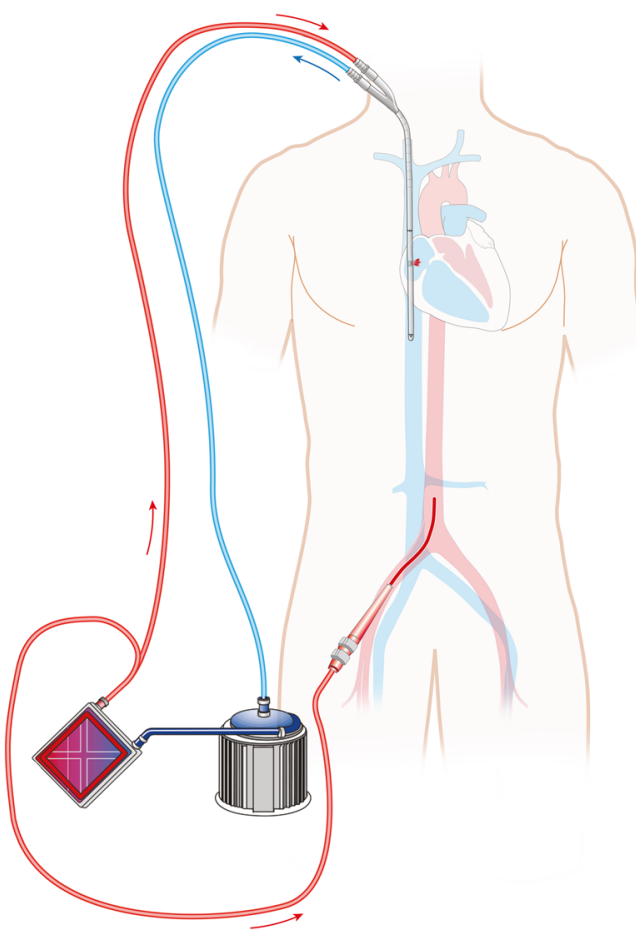

Fig. 6 Showing how an Avalon dual-lumen ECMO cannula can be used in a hybrid (VAV) (veno-arterial-venous) configuration

12th rib (T12-L1 junction- 12th thoracic- 1st lumbar) (Fig. 7). This position best aligns the flow from the return port towards the TV. Either TTE or TEE can confirm location during or immediately after insertion. We use both fluoroscopy and

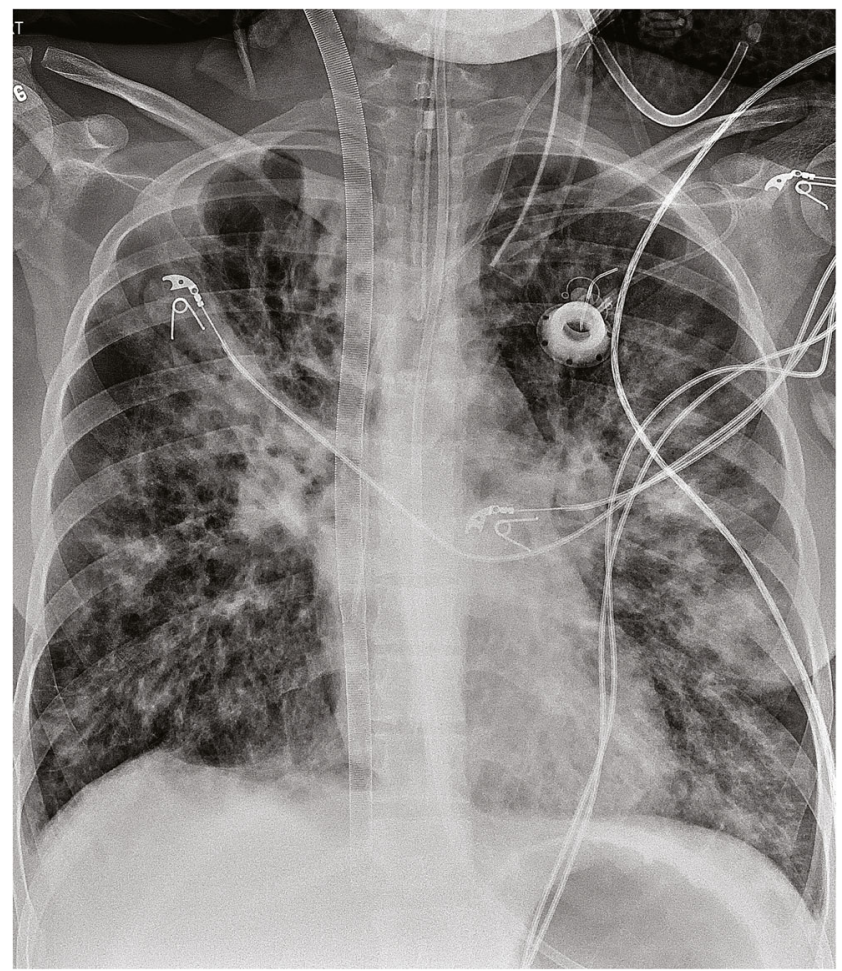

Fig. 7 X-ray showing the Avalon dual-lumen ECMO cannula after insertion 
TEE if the insertion is done electively in the OR. It is possible to insert at the bedside using ultrasound guidance or serial $\mathrm{X}$ rays. The return limb of the (dl) VV orients antero-superiorly by design to direct the reinfused blood towards the TV.

Of note, we perform daily chest and abdomen X-rays to check cannula position. If the cannula migrates either waythat is too shallow in the IVC or too deep-recirculation can develop since the return port is no longer aligned with the TV.

\section{Some disadvantages of ECMO and potential issues with large-bore cannulation}

Intracranial hemorrhage is a dreaded complication of all modalities of ECMO. Insertion of a large-bore cannula into the IJ can possibly increase cerebral venous pressure promoting hemorrhage. A review of the ELSO registry (2011-2016) comparing propensity-matched VV ECMO patients cannulated with the Avalon Elite 27 Fr. $(n=372)$ or 31 Fr. $(n=$ 372) found the rate of intracranial hemorrhage was 3 times higher in those cannulated with the larger catheter $(n=16$, $4.3 \%$ v. $n=6,1.6 \%, p=0.03$ ). These results suggest the use of the smallest cannula able to achieve adequate ECMO flow to minimize the risk of intracranial hemorrhage [20].

\section{Post ECMO management of anticoagulation}

A bolus dose of heparin is given prior to cannulation. After the first $24 \mathrm{~h}$ of systemic anticoagulation, we have shifted to a protocol of using Bivalirudin with the goal of maintaining the activated partial thromboplastin time (APTT) 45-75 s. Some centers question the need for anticoagulation with ECMO, reporting no increase in mortality, pump failure, or thrombotic complications in ECMO support without systemic anticoagulation [29]. We individualize anticoagulation based on our center's protocol, in conjunction with the ICU team and the Pharmacy team's input.

(dl)VV ECMO is used during lung transplantation for total gas exchange before, during, and after transplantation. If cardiopulmonary bypass (CPB) or VA ECMO is needed for additional cardiac support during the transplant, the DLC can be used for venous drainage and an arterial reinfusion cannula is added [29]. The caveat here is if the pump run is long there is a chance of thrombosis in the return lumen and so the options are to use a new circuit for the cardiopulmonary bypass and keep the DL-VV ECMO circuit in recirculation mode [30].

Before insertion, we prefer to prep and drape both the neck and groins. This prepares the patient for emergent femoral cannulation in case of insertion complications. Ultrasound guidance directs puncture of the RIJ and confirms needle positioning. A floppy guidewire is passed into the IVC and beyond, then using the Seldinger technique, serial dilations are performed under fluoroscopic and/or TTE insertion guidance allows cannula insertion.
Inadequate dilation can lead to a kink in the guidewire and stall insertion or redirect the cannula. In order to decrease resistance at the skin and fascia, we sometimes use a Ciaglia Blue Rhino®-Cook Medical tracheal dilator from the percutaneous tracheostomy kit. At any point, if resistance is felt, we recommend backing out the dilator and repeating the process with the smaller dilator before proceeding with larger sizes. To avoid displacement or perforation during final catheter insertion, the guidewire is visualized low in the IVC beyond the renal veins or even into the iliac using image guidance. A Glidecath ( 5 Fr., $100 \mathrm{~cm}$, Terumo Medical Somerset, NJ) can be a useful tool to help change wires from a floppy to an Amplatz Super Stiff guidewire 0.038 in.; $210 \mathrm{~cm}$ ) and serial dilators (10 to $30 \mathrm{Fr}$.). The introducer is removed, then serial dilation of the subcutaneous tract and IJ vein is performed to assure smooth passage along the guidewire. Once the subcutaneous tissue and IJ vein are dilated to the appropriate caliber, the Avalon Elite ${ }^{\mathrm{TM}}$ cannula is introduced over the Super Stiff guidewire and advanced into position. Fluoroscopic navigation is still necessary as the cannula advances into position. The recognizable silhouette of a pulmonary artery (PA) catheter as it traverses the TV may aid proper alignment of the cannula reinfusion port with the TV. After connection with the ECMO circuit, directional inflow across the TV may be assessed by TEE. We recommend maintaining the hematocrit close to $30 \%$ and hemoglobin near $10 \mathrm{~g} / \mathrm{dL}$. Ideally, crossmatched blood (preferably irradiated and cytomegalovirus negative) is made available prior to ECMO initiation, to anticipate compensating for hemodilution from the circuit priming volume. Note that hemodilution is exaggerated when a tubing extension is added to the circuit to aid mobility, trips to the scanner, or Cath lab.

\section{Protek-duo LS (oxyRVAD) (right ventricular assist de- vice with an oxygenator)}

The Protek-Duo (CardiacAssist Inc., LivaNova, Pittsburgh, PA) is a double-lumen cannula that can be used for providing VV ECMO support; the Protek-Duo traverses the SVC, RA, and right ventricular (RV) and rests in the main PA beyond the pulmonary valve (PV). It drains venous blood from the RA and reinfuses blood in the main PA and has the added benefit of unloading the RV [31].

In select cases of pulmonary hypertension with RV failure, the Protek-Duo is connected to a membrane oxygenator in a form of ECLS called oxyRVAD [32]. It is inserted percutaneously via the RIJ with the inflow portion in the RA and the outflow portion of the cannula positioned either in the right $\mathrm{PA}$ or in the main PA [33].

Available in two sizes, the 29F ProtekDuo-5720-2916 and 31F 5720-3118 can achieve around 4-4.5 L flows (Fig. 8). Placement requires fluoroscopic guidance and is performed either in the Cath lab or in an OR setting using portable C- 
arm fluoroscopy. While we prefer to perform elective placement in the Cath lab, we have placed it in the OR also although less frequently. It is important to check the cannula position by performing daily $\mathrm{X}$-rays and pay close attention to the tip of the cannula. We have noticed cannula migration into the left $\mathrm{PA}$ or into the $\mathrm{RV}$ associated with hemodynamic or radiologic changes requiring prompt attention.

The advantages are similar to the dual-lumen ECMO cannula permitting early extubation and ambulation. Early mobilization prevents deconditioning, muscle wasting, thromboembolism, and infection. It can be easily decannulated at the bedside [31].

However, there is a need for an experienced operator with wire skills. We check cannula position by performing daily Xrays; one must be alert to the possibility of displacement into the left PA or into the RV.

\section{VV ECMO}

\section{Central oxy RVAD/VV ECMO (mini sternotomy and RA to PA via oxygenator)}

Indications In patients requiring more oxygenation, when conventional VV ECMO is inadequate to mitigate hypoxia, either due to the native shunt or the inability to flow at higher rates and the constant requirement for sedation/ paralytic thereby limiting the chances of meaningful participation in physical therapy which leads to muscle wasting and deconditioning; Central VV ECMO is a useful alternative.

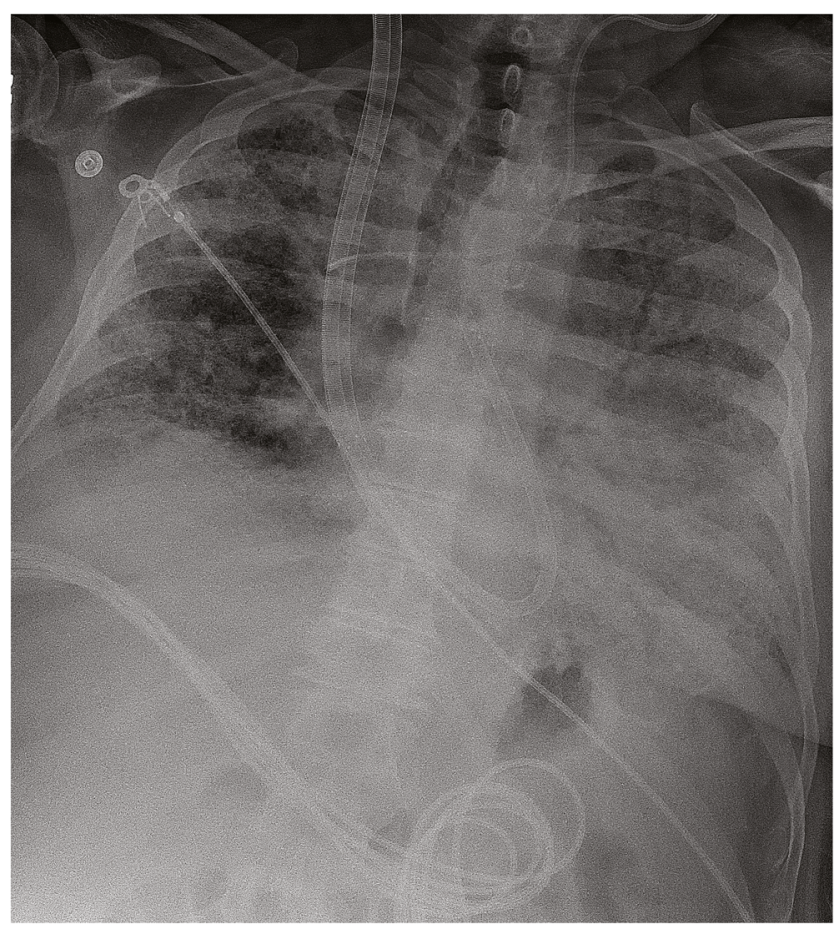

Fig. 8 Protek-Duo cannula in the main PA
Technique Lower mini sternotomy is preferred but can be done via sternotomy keeping the incision at the level of the manubrium/angle of Louis. Avoid excessive opening of the pericardium or exposing the innominate vein. Oftentimes, these patients have a tracheostomy or might need one which is the reason to stay as low as possible such that the tissue planes do not communicate.

Pledgetted purse-strings are taken on RA and small pledgets on the PA; we use a malleable wire-reinforced cannula, $32 \mathrm{~F}$ for the RA, Medtronic David Lynda Philip cannula (DLPß) REF 68132 and a Medtronic 20F Elongated One-Piece Arterial cannula (EOPA) 3D® REF 78220 cannula for the PA; the cannulae are tunneled from the sub-xiphoid space; we use a 36-F chest tube to deliver the cannulae into the chest to avoid entrapping fat/loose areolar tissue in the cannulae; excellent and unimpeded drainage is achieved; these patients can be liberated from the ventilator once the sedation is weaned off.

An alternative technique is to sew an 8-mm Dacron graft to the main PA and cannulate the graft with a $20-\mathrm{F}$ or $24-\mathrm{F}$ cannula. The cannula is secured to the graft at multiple points using heavy silk ties and it is pushed far enough such that the graft itself does not kink. When the patient is weaned off ECMO support, the graft can be amputated and sewn with 5/ 0 polypropylene or stapled off leaving a small nubbin.

It is possible to ambulate these patients and enable participation in physical therapy although this is easier said than done and involves a comprehensive multidisciplinary effort involving ECMO specialists/ Perfusionists/ Respiratory therapists/Nurses/Nutritionists and Intensive Care Specialists.

The ECMO circuit can be used during transplant; we have employed bilateral thoracotomy during the transplant although a thoraco-sternotomy (clamshell) approach can be undertaken paying close attention to the cannulae. It is easy to convert to central VA ECMO or CPB should the need arise and is easy to decannulate (Fig. 9).

Potential complications - cannula movement or displacement, bleeding, and need for emergent sternal re-entry.

A pumpless lung assist device, PA (left atrium)-LA oxygenator, has been inserted via a left thoracotomy; this has been utilized in cases of severe pulmonary arterial hypertension (PAH) and hypercapnia/hypoxia [34].

VA ECMO When there is a hypoxemic respiratory failure with hypercapnia and RV failure due to severe $\mathrm{PAH}$, we have seen that conventional ECMO strategies are inadequate and the choice for a meaningful bridge is VA ECMO which can be either axillary or central.

Peripheral (VA ECMO) can be used as a bridge to lung transplantation. The femoral artery and vein are accessed with ultrasound guidance. We suggest getting distal perfusion access prior to cannulating the femoral artery especially when 
Fig. 9 The panel on the left shows the approach - a lower mini sternotomy, manubrium sparing. The panel on the right shows the cannulation of the RA and PA with the cannulae being tunneled like chest tubes beneath the xiphoid so that the chest can be closed

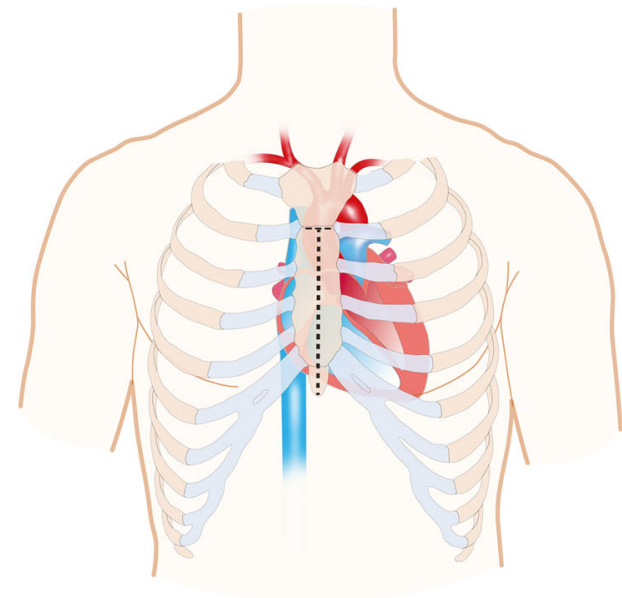

the procedure is elective. When antegrade access for distal perfusion is difficult due to patient anatomy or depth of the vessel, we have used retrograde access via the posterior tibial artery. We recommend the use of oximetry probes on the legs to identify the early onset of ischemia. Limb complications can be minimized with the use of a side graft onto the femoral artery [35].

This has served as the first step in our approach before we transition to central VA ECMO.

Common issues with peripheral VA ECMO are in need for distal limb perfusion, difficulties with mobilization, limb complications, and cerebral or upper body hypoxia due to the onset of North-South (Harlequin) syndrome/distribution watershed-which limits this approach from the general application. There is also the concern of athero-embolism with retrograde perfusion. Conformational changes in the circuit can be adopted by adding an additional venous cannula in the neck to perfuse oxygenated blood to the heart to alleviate upper body hypoxia; however, it is often difficult to manage the flows into the femoral and neck cannula as it depends on the systemic and pulmonary vascular resistance.

\section{Axillary inflow/femoral venous outflow VA ECMO}

In order to avoid limb complications with femoral arterial cannulation using the axillary artery for the inflow is an attractive alternative. The axillary artery is approached via a cutdown; an $8 \mathrm{~mm}$ Dacron graft is sewn after adequately beveling the graft to prevent preferential flow to the limb and avoid hyperperfusion [36].

The graft is tunneled and the length kept short; adequate hemostasis is paramount.

The advantages of this approach provide for ambulation and easy to institute and can be used for long-term support; the size of the return cannula is not an issue since the inflow is through an 8-mm Dacron graft and ischemic complications are less compared to femoral VA ECMO (Fig. 10). Complications include hematoma/brachial plexus injury/ venous compression/limb hyperperfusion and stroke.

However, emerging literature suggests that femoral cannulation itself would not preclude mobility. In their experience, mobilizing and ambulating patients with femoral cannulation were feasible and safe [11].

\section{Central VA ECMO via right mini-thoracotomy (RA aorta)}

Central cannulation is instituted when long-term support is desirable with the added advantage of ambulation and reliable oxygenation. Central cannulation provides antegrade flow through the aorta while allowing excellent venous drainage from the RA. This can be performed through a right mini anterior thoracotomy and allows the patient to wean from the ventilator and has the flexibility of enabling participation in physical therapy [37].

The cannulae are tunneled through the intercostal spaces to reduce the risk of blood-borne infections and spare the sternum for future operations. Central cannulation can also be done via a median sternotomy or partial sternotomy.

For a right mini-thoracotomy central VA ECMO, the approach is through the 3 rd intercostal space; the cartilage can be disarticulated and the right internal mammary artery might need to be clipped and divided. The pericardium then comes into view and is incised anterior to the phrenic nerve to expose the ascending aorta and the right atrial appendage. Pledgeted purse strings are placed on the aorta; we use 2 purse-string sutures with $3 / 0$ polypropylene and have 2 pledgets for each purse string so that we have 4 pledgets in all for the aortic cannulation at the 4 corners of an imaginary diamond. Similarly, 2 pledgeted purse-strings are taken on the right atrial appendage if the appendage is well-formed or else on the body of the RA. We have used a Medtronic 20F EOPA $3 \mathrm{D} \circledast \mathrm{REF} 78220$ cannula for the aorta and a 32F Medtronic 
Fig. 10 VA ECMO configuration with drainage from the RFV and return via the right axillary artery; inset on the right showing the right axillary graft
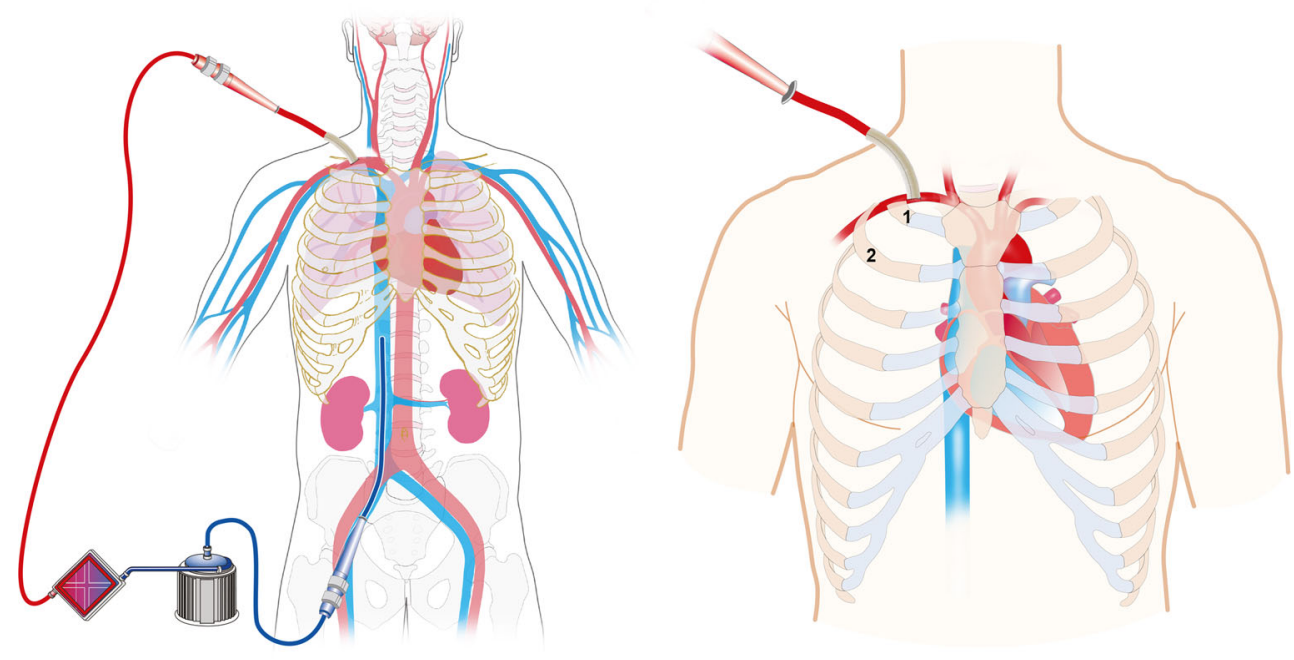

DLP® REF 68132 cannula for the RA; alternatively, an angled metal tip cannula can be used for the RA. The cannulae are delivered via the intercostal spaces; one space below the thoracotomy for the aortic cannula and 2 spaces below for the RA.

We have used a large-bore chest tube to deliver the cannulae into the chest to avoid entrapping loose adipose tissue. The main predicament is how to keep the cannulae in position with the chest closed; buttons have been used by [37]. We have used tourniquets-DLP Medtronic 79012 TourniKwik ${ }^{\mathrm{TM}}$ which can enable the purse strings to be cinched and snugly hold the cannulae in place without the need to leave behind 4 hemostats in the chest. In addition, we use multiple medium clips to crimp the tourniquet's and have also used multiple silk ties to ensure the snares are tight; however, there is a potential for cannula dislodgement especially with ambulation and that has to be borne in mind. The cannulae are secured to the chest wall prior to chest closure and also to the skin at multiple sites.

This technique offers several advantages; it allows for central aortic cannulation and antegrade blood flow while unloading the RV and enabling right heart recovery. Tunneled cannulation technique minimizes the risk of catheter-borne infection, allowing long-term use and ambulation (Fig. 11). It can be performed via a minimally invasive approach. Potential complications associated with this technique include bleeding, cannula dislodgement, and technical challenges during re-entry of the chest for transplant (Fig. 12).

\section{Discussion}

Lung transplantation is an accepted treatment option for patients with end-stage lung disease. For those patients who present with a rapid decline in respiratory status, they must be stabilized before transplantation status can be established.
These patients have a high rate of in-hospital mortality, and their candidacy for lung transplantation must be urgently assessed [38-40].

Donor lungs are a scarce resource and bridging strategies may be necessary for survival and thoughtful assessment for lung transplantation. The indication for ECMO is determined by the patient's candidacy for lung transplantation. If the patient is clearly not a candidate and has an irreversible process, then ECMO should be avoided. If the patient is already on the waitlist, and irreversible end-organ damage or other conditions that would preclude him or her from remaining on the list have not developed, then ECMO is certainly an option [41]. The more challenging scenarios involve those patients who are somewhere in between, such as a patient who is not yet cleared for transplantation, or if it is unclear whether a patient's critical illness is reversible. In such cases, ECMO can be used as a bridge to decisions.

A report on the US trends in bridging outcomes by Hayanga and colleagues showed that in 2000-2002, the 1year survival rate after ECMO BTT was $25 \%$, which was increased to $74 \%$ in 2009-2011 [42]. Multiple single-center reviews have been published in the last decade. In 2020, the University of California San Francisco published their experience from 2010 to 2018 bridging patients to lung transplant with ECMO. Over the study period, 436 lung transplants were performed, and 76 patients were placed on ECMO as BTT. Of the 76 patients, 42 were waitlisted before ECMO initiation, 20 were emergently waitlisted after ECMO initiation, and 14 patients failed to list after ECMO initiation. There was no significant outcome difference for those bridged before or after listing. Of the 62 patients successfully waitlisted and bridged, 42 were successfully transplanted. Post-transplant 30-day survival was $98 \%$ and 1-year survival conditional upon discharge was $97 \%$ [43].

Another 2020 study conducted at a tertiary care center in Brazil reported a 10 -year experience with perioperative 
Fig. 11 Panel on the left showing the approach via the $3 \mathrm{rd}$ right intercostal space; panel on the right showing the exposure and the arterial (aortic) and venous (right atrial) cannulae being tunneled through the intercostal spaces
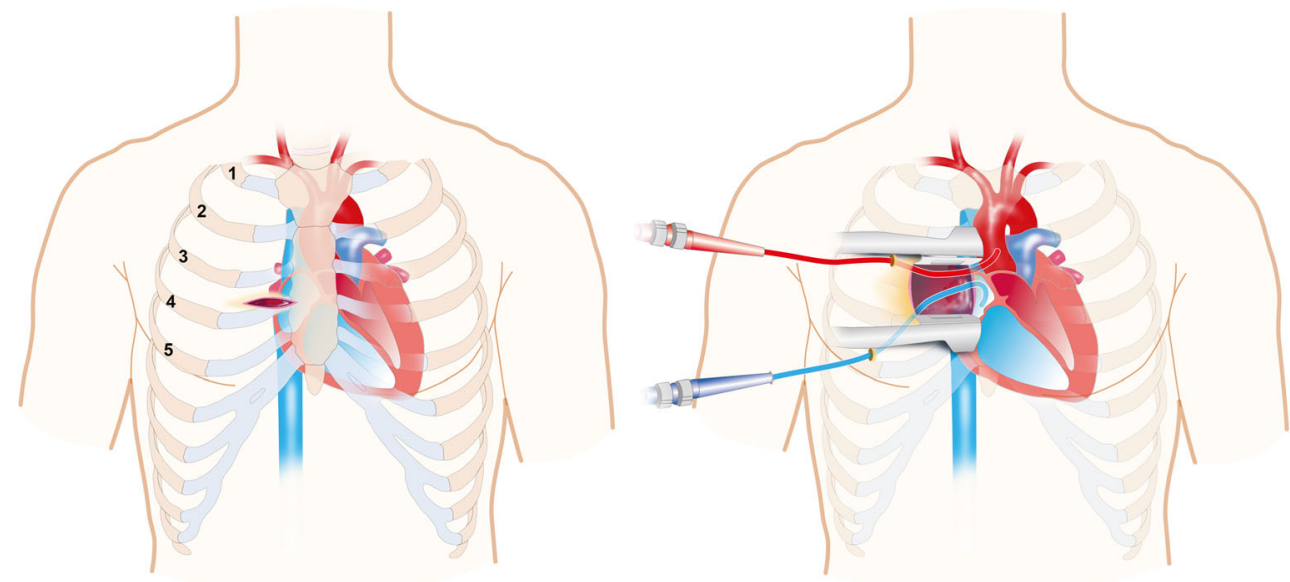

ECMO. Authors showed $10 \%$ of lung transplant cases $(n=8)$ were supported with ECMO as a bridge $(n=1)$, during surgery $(n=5)$, or postoperatively $(n=2)$. The mean ECMO duration was $9.3 \pm 6.6$ days (range $2-18$ days) with a $50 \%(n=4 /$ $8)$ decannulation rate. Survival to discharge was $38 \%(n=3 / 8)$ and included the bridged patient. The 3 patients discharged were still alive at 1 year [44].

A 2012 study by Lang and colleagues [45] conducted in Vienna, Austria, bridged 38 patients to lung transplant with a $90 \%$ success rate but a $24 \%$ rate of in-hospital mortality after transplant. The median bridging time was 5.5 days (range, 1-63 days). Patients who were bridged and survived the initial 3-month period after transplant had a 5year survival rate that was equivalent to that of patients who were not bridged (63\% vs $72 \%, p=.33$ ) (58).

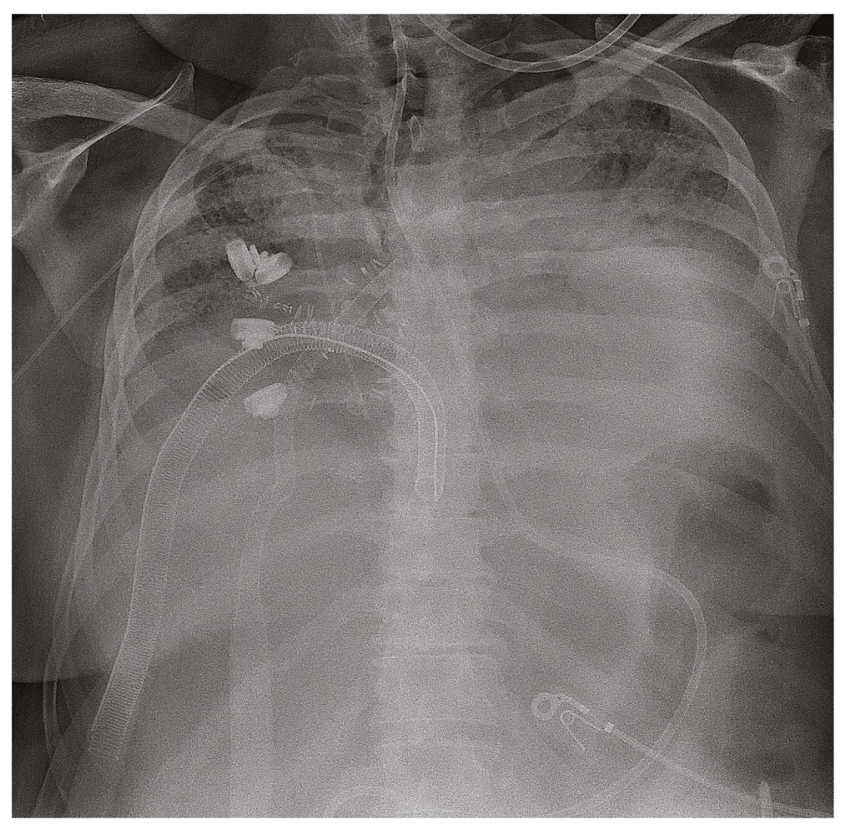

Fig. 12 X-ray showing the cannulae positioned in the aorta and RA; note the patient has been extubated
Biscotti and colleagues reported their 9-year experience at New York-Presbyterian/Columbia University Medical Center with a $55 \%$ success rate for bridging to transplant with ECMO [46]. The University of Pittsburgh Medical Center bridged 31 patients to transplant on ECMO over a 6-year period, with 25 ultimately surviving to transplantation. Of the patients successfully bridged, they demonstrated a $74 \%$ 2-year survival compared with $74 \%$ for unsupported patients [47]. The variation of success emphasizes the importance of selecting patients who are most likely to tolerate perioperative ECMO. While dwelling on the topic of BTT in cystic fibrosis patients, Hayes et al. [48] recommend that ambulatory VV ECMO using a single venous cannula be used in patients with hypercapnic respiratory failure. The ability to participate in physical therapy and being able to eat obviated the need for sedation while on ECMO while also avoiding the deleterious effects of mechanical ventilation such as barotrauma.

A special population of patients with pre-existing RV dysfunction from pulmonary hypertension is at risk of RV failure from increased pulmonary vascular resistance from hypoxemia, hypercarbia, or intraoperative clamping of the PA during lung transplant. The Protek-duo is useful as a bridge to bilateral lung transplant in this subset of patients. Budd and colleagues published a case report of a 53-year-old female with PAH secondary to systemic scleroderma supported with the Protek-duo. The patient was intraoperatively supported with VA ECMO, using both lumens of the Protek-duo cannula to achieve adequate venous drainage and an additional arterial reinfusion cannula was placed in the ascending aorta. Postoperatively, the arterial cannula was removed and the patient was maintained on VV ECMO with the Protek-duo in an oxyRVAD configuration due to concerns for acute rejection. The patient was successfully decannulated on post-operative day 6 [49].

VA ECMO can be used in patients with PAH, especially those with evidence of RV dysfunction, and has been 
used to offload the RV while enabling adequate oxygenation and perfusion [50]. While conventionally it has been used in a femoral configuration, there are potential issues which can compound the problem: limb ischemia, malperfusion due to North-South syndrome, inability to mobilize being some of the major drawbacks [51]. Alternative configurations such as draining through the right $\mathrm{IJ}$ and perfusing through the right subclavian artery are attractive. However, this has the additional disadvantage of inserting a large-bore cannula in the neck for drainage and also the risk of upper limb hyperperfusion [36]. Central access appears to avoid the disadvantages associated with VA ECMO while maintaining antegrade perfusion and unimpeded return. This has been accomplished with a small right thoracotomy [37, 52] enabling direct aortic and right atrial cannulation with the ability to ambulate and participate in physical therapy. There is a potential risk of stroke with aortic manipulation/ cannulation which is also present with retrograde perfusion via the femoral route- $5 \%$ in the series from Kukreja et al. [43] who reported a $98 \%$ 30-day survival in a series of 42 patients who were successfully BTT compared to $88 \%$ and $93 \%$ from other centers $[50,53]$.

In a retrospective study at the Duke University Medical Center, subjects supported with ambulatory ECMO had a $22 \%$ reduction in total hospital cost, $73 \%$ reduction in posttransplant ICU cost, and $11 \%$ reduction in total cost when compared with non-ambulatory ECMO subjects demonstrating the added economic benefit of an ambulatory ECMO strategy [54]. Another retrospective study from the Cleveland Clinic showed that an awake and ambulatory strategy with aggressive physical therapy might increase success as a BTT and perhaps improve long-term outcomes. Arguing that even though only a fraction of their patients on ECMO were successfully ambulated and spontaneously breathe this subset had an accelerated recovery [55].

\section{Conclusions}

ECMO BTT has come of age and is a useful tool when initiated before irreversible debilitation and end-organ failure develop. Despite the challenges of ECMO bridging to transplant, the availability of newer tools and techniques have facilitated the management of this subset of patients who otherwise have no other alternative while they wait for donor lungs. Ambulatory ECMO has further refined these strategies to help early mobilization and promote participation in physical therapy while optimizing patients as they are successfully bridged to transplantation.
Acknowledgements We acknowledge the contributions of Mr. Thomas Dolan, Medical Illustrator, University of Kentucky College of Medicine, for his help with illustrations.

Funding None.

\section{Declarations}

Ethics approval Waiver obtained from the University of Kentucky IRB.

Consent for publication Obtained.

Conflict of interest The authors declare no competing interests.

Author contribution SK: conceived the topic/literature search/manuscript writing/editing/finalizing; VB: manuscript writing; TAT: help with data collection; MAB: data collection, review; JBZ: review, guidance.

\section{References}

1. Yeo HJ, Lee S, Yoon SH, et al. Extracorporeal life support as a bridge to lung transplantation in patients with acute respiratory failure. Transplant Proc. 2017;49:1430-5.

2. Makdisi G, Wang I-W. Extra Corporeal Membrane Oxygenation (ECMO) review of a lifesaving technology. J Thorac Dis. 2015;7: E166-E76. https://doi.org/10.3978/j.issn.2072-1439.2015.07.17.

3. Weill D, Benden C, Corris PA, et al. A consensus document for the selection of lung transplant candidates: 2014-an update from the Pulmonary Transplantation Council of the International Society for Heart and Lung Transplantation. J Heart Lung Transplant. 2015;34: 1-15. https://doi.org/10.1016/j.healun.2014.06.014.

4. Peek GJ, Mugford M, Tiruvoipati R, et al. Efficacy and economic assessment of conventional ventilatory support versus extracorporeal membrane oxygenation for severe adult respiratory failure (CESAR): a multicentre randomised controlled trial. Lancet. 2009;374:1351-63. https://doi.org/10.1016/S0140-6736(09) 61069-2.

5. Davies A, Jonas D, Bailey M, et al. Extracorporeal Membrane Oxygenation for 2009 Influenza A(H1N1) acute respiratory distress syndrome. JAMA. 2009;302:1888-95. https://doi.org/10.1001/ jama.2009.1535.

6. Noah MA, Peek GJ, Finney SJ, et al. Referral to an extracorporeal membrane oxygenation center and mortality among patients with severe 2009 influenza A (H1N1). JAMA. 2011;306:1659-68.

7. Combes A, Pellegrino V. Extracorporeal Membrane Oxygenation for 2009 Influenza A (H1N1)-associated acute respiratory distress syndrome. Semin Respir Crit Care Med. 2011;32:188-94.

8. Hayanga JWA, Hayanga HK, Holmes SD, et al. Mechanical ventilation and extracorporeal membrane oxygenation as a bridge to lung transplantation: Closing the gap. J Heart Lung Transplant. 2019;38:1104-11. https://doi.org/10.1016/j.healun.2019.06.026.

9. Naito N, Cook K, Toyoda Y, Shigemura N. Artificial lungs for lung failure: JACC technology corner. J Am Coll Cardiol. 2018;72: 1640-52. https://doi.org/10.1016/j.jacc.2018.07.049.

10. Pasrija C, Mackowick KM, Raithel M, et al. Ambulation with femoral arterial cannulation can be safely performed on venoarterial extracorporeal membrane oxygenation. Ann Thorac Surg. 2019;107:1389-94.

11. Shudo Y, Kasinpila P, Lee AM, Rao VK, Woo YJ. Ambulating femoral venoarterial extracorporeal membrane oxygenation bridge to heart-lung transplant. J Thorac Cardiovasc Surg. 2018;156: e135-7. https://doi.org/10.1016/j.jtcvs.2018.03.002. 
12. Jayaraman AL, Cormican D, Shah P, Ramakrishna H. Cannulation strategies in adult veno-arterial and veno-venous extracorporeal membrane oxygenation: techniques, limitations, and special considerations. Ann Card Anaesth. 2017;20:S11-8.

13. Schweickert WD, Pohlman MC, Pohlman AS, et al. Early physical and occupational therapy in mechanically ventilated, critically ill patients: a randomised controlled trial. Lancet. 2009;373:1874-82.

14. Turner DA, Cheifetz IM, Rehder KJ, et al. Active rehabilitation and physical therapy during extracorporeal membrane oxygenation while awaiting lung transplantation: a practical approach. Crit Care Med. 2011;39:2593-8. https://doi.org/10.1097/CCM. 0b013e3182282bbe.

15. Rehder KJ, Turner DA, Hartwig MG, et al. Active rehabilitation during extracorporeal membrane oxygenation as a bridge to lung transplantation. Respir Care. 2013;58:1291-8.

16. Ko Y, Cho YH, Park YH, et al. Feasibility and safety of early physical therapy and active mobilization for patients on extracorporeal membrane oxygenation. ASAIO J. 2015;61:564-8.

17. Wells CL, Forrester J, Vogel J, Rector R, Tabatabai A, Herr D. Safety and feasibility of early physical therapy for patients on extracorporeal membrane oxygenator: University of Maryland Medical Center Experience. Crit Care Med. 2018;46:53-9. https:// doi.org/10.1097/CCM.0000000000002770.

18. Hodgson CL, Stiller K, Needham DM, et al. Expert consensus and recommendations on safety criteria for active mobilization of mechanically ventilated critically ill adults. Crit Care. 2014;18:658. https://doi.org/10.1186/s13054-014-0658-y.

19. Kohler K, Valchanov K, Nias G, Vuylsteke A. ECMO cannula review. Perfusion. 2013;28:114-24.

20. Mazzeffi M, Kon Z, Menaker J, et al. Large dual-lumen extracorporeal membrane oxygenation cannulas are associated with more intracranial hemorrhage. ASAIO J. 2019;65:674-7. https://doi.org/ 10.1097/MAT.0000000000000917.

21. Dzierba AL, Abel EE, Buckley MS, Lat I. A review of inhaled nitric oxide and aerosolized epoprostenol in acute lung injury or acute respiratory distress syndrome. Pharmacotherapy. 2014;34:279-90. https://doi.org/10.1002/phar.1365.

22. Torbic H, Szumita PM, Anger KE, Nuccio P, LaGambina S, Weinhouse G. Inhaled epoprostenol vs inhaled nitric oxide for refractory hypoxemia in critically ill patients. J Crit Care. 2013;28: 844-8. https://doi.org/10.1016/j.jcrc.2013.03.006.

23. McGinn K, Reichert M. A comparison of inhaled nitric oxide versus inhaled epoprostenol for acute pulmonary hypertension following cardiac surgery. Ann Pharmacother. 2016;50:22-6.

24. Zhao J, Wang D, Ballard-Croft C, et al. Hybrid extracorporeal membrane oxygenation using avalon elite double lumen cannula ensures adequate heart/brain oxygen supply. Ann Thorac Surg. 2017;104:847-53. https://doi.org/10.1016/j.athoracsur.2017.01. 119.

25. Shaheen A, Tanaka D, Cavarocchi NC, Hirose H. Veno-Venous Extracorporeal Membrane Oxygenation (V V ECMO): Indications, preprocedural considerations, and technique. J Card Surg. 2016;31: 248-52.

26. Ngai C-W, Ng PY, Sin W-C. Bicaval dual lumen cannula in adult veno-venous extracorporeal membrane oxygenation-clinical pearls for safe cannulation. J Thorac Dis. 2018;10:S624-8. https://doi.org/ 10.21037/jtd.2018.02.70.

27. Rubino A, Vuylsteke A, Jenkins DP, Fowles J-A, Hockings L, Valchanov K. Direct complications of the Avalon bicaval duallumen cannula in respiratory extracorporeal membrane oxygenation (ECMO): single-center experience. Int $\mathbf{J}$ Artif Organs. 2014;37:741-7.

28. Tignanelli CJ, Weinberg A, Napolitano LM. Optimal methods to secure extracorporeal membrane oxygenation bicaval dual-lumen cannulae: What works? ASAIO J. 2019;65:628-30.
29. Bacchetta M, Javidfar J, Sonett J, Kim H, Zwischenberger J, Wang D. Ease of conversion from venovenous extracorporeal membrane oxygenation to cardiopulmonary bypass and venoarterial extracorporeal membrane oxygenation with a bicaval dual lumen catheter. ASAIO J. 2011;57:283-5.

30. Hashimoto K, Hoetzenecker K, Yeung JC, et al. Intraoperative extracorporeal support during lung transplantation in patients bridged with venovenous extracorporeal membrane oxygenation. J Heart Lung Transplant. 2018;37:1418-24. https://doi.org/10. 1016/j.healun.2018.07.003.

31. Aggarwal V, Einhorn BN, Cohen HA. Current status of percutaneous right ventricular assist devices: First-in-man use of a novel dual lumen cannula. Catheter Cardiovasc Interv. 2016;88:390-6. https:// doi.org/10.1002/ccd.26348.

32. Kirklin JK, Pagani FD, Goldstein DJ, et al. American Association for Thoracic Surgery/International Society for Heart and Lung Transplantation guidelines on selected topics in mechanical circulatory support. J Heart Lung Transplant. 2020;39:187-219.

33. Schmack B, Weymann A, Popov A-F, et al. Concurrent Left Ventricular Assist Device (LVAD) implantation and percutaneous temporary RVAD support via CardiacAssist Protek-Duo TandemHeart to preempt right heart failure. Med Sci Monit Basic Res. 2016;22:53-7. https://doi.org/10.12659/MSMBR.898897.

34. Strueber M, Hoeper MM, Fischer S, et al. Bridge to thoracic organ transplantation in patients with pulmonary arterial hypertension using a pumpless lung assist device. Am J Transplant. 2009;9: 853-7. https://doi.org/10.1111/j.1600-6143.2009.02549.x.

35. Keshavamurthy S, Shafii AE, Soltesz E. Spectroscopic limb monitoring in peripheral extracorporeal membrane oxygenation. Asian Cardiovasc Thorac Ann. 2015;23:347-8. https://doi.org/10.1177/ 0218492314539523.

36. Chamogeorgakis T, Lima B, Shafii AE, et al. Outcomes of axillary artery side graft cannulation for extracorporeal membrane oxygenation. J Thorac Cardiovasc Surg. 2013;145:1088-92. https://doi. org/10.1016/j.jtcvs.2012.08.070.

37. Downey P, Ragalie W, Gudzenko V, Ardehali A. Ambulatory central veno-arterial extracorporeal membrane oxygenation in lung transplant candidates. J Heart Lung Transplant. 2019;38:1317-9. https://doi.org/10.1016/j.healun.2019.09.006.

38. Blivet S, Philit F, Sab JM, et al. Outcome of patients with idiopathic pulmonary fibrosis admitted to the ICU for respiratory failure. Chest. 2001;120:209-12.

39. Mollica C, Paone G, Conti V, et al. Mechanical ventilation in patients with end-stage idiopathic pulmonary fibrosis. Respiration. 2010;79:209-15.

40. Rangappa P, Moran JL. Outcomes of patients admitted to the intensive care unit with idiopathic pulmonary fibrosis. Crit Care Resusc. 2009;11:102-9.

41. Rajagopal K, Hoeper MM. State of the Art: Bridging to lung transplantation using artificial organ support technologies. J Heart Lung Transplant. 2016;35:1385-98. https://doi.org/10.1016/j.healun. 2016.10.005.

42. Hayanga AJ, Aboagye J, Esper S, et al. Extracorporeal membrane oxygenation as a bridge to lung transplantation in the United States: an evolving strategy in the management of rapidly advancing pulmonary disease. J Thorac Cardiovasc Surg. 2015;149:291-6. https://doi.org/10.1016/j.jtcvs.2014.08.072.

43. Kukreja J, Tsou S, Chen J, et al. Risk factors and outcomes of extracorporeal membrane oxygenation as a bridge to lung transplantation. Semin Thorac Cardiovasc Surg. 2020;32:772-85.

44. Pola-Dos-Reis F, Samano MN, Abdalla LG, et al. Extracorporeal membrane oxygenation and lung transplantation: initial experience at a single Brazilian center. Clinics (Sao Paulo). 2020;75:e1698.

45. Lang G, Taghavi S, Aigner C, et al. Primary lung transplantation after bridge with extracorporeal membrane oxygenation: a plea for a 
shift in our paradigms for indications. Transplantation. 2012;93: 729-36.

46. Biscotti M, Gannon WD, Agerstrand C, et al. Awake extracorporeal membrane oxygenation as bridge to lung transplantation: A 9-year experience. Ann Thorac Surg. 2017;104:412-9. https://doi.org/10. 1016/j.athoracsur.2016.11.056.

47. Toyoda Y, Bhama JK, Shigemura N, et al. Efficacy of extracorporeal membrane oxygenation as a bridge to lung transplantation. $\mathrm{J}$ Thorac Cardiovasc Surg. 2013;145:1065-71.

48. Hayes D, Kukreja J, Tobias JD, Ballard HO, Hoopes CW. Ambulatory venovenous extracorporeal respiratory support as a bridge for cystic fibrosis patients to emergent lung transplantation. J Cyst Fibros. 2012;11:40-5. https://doi.org/10.1016/j.jcf.2011.07. 009.

49. Budd AN, Kozarek K, Kurihara C, Bharat A, Reynolds A, Kretzer A. Use of ProtekDuo as veno-arterial and veno-venous extracorporeal membrane oxygenation during bilateral lung transplantation. $\mathrm{J}$ Cardiothorac Vasc Anesth. 2019;33:2250-4. https://doi.org/10. 1053/j.jvca.2018.12.025.

50. Banga A, Batchelor E, Mohanka M, et al. Predictors of outcome among patients on extracorporeal membrane oxygenation as a bridge to lung transplantation. Clin Transplant. 2017;31. https:// doi.org/10.1111/ctr.12990.

51. Abrams DC, Brodie D, Rosenzweig EB, Burkart KM, Agerstrand CL, Bacchetta MD. Upper-body extracorporeal membrane oxygenation as a strategy in decompensated pulmonary arterial hypertension. Pulm Circ. 2013;3:432-5. https://doi.org/10.4103/ 2045-8932.113178.

52. Singh SK, D'Ovidio F, Garan AR, et al. Minimally invasive central venoarterial extracorporeal membrane oxygenation for long-term ambulatory support as a bridge to heart-lung transplant. J Artif Organs. 2020;23:394-6. https://doi.org/10.1007/s10047-02001198-5.

53. Tipograf Y, Salna M, Minko E, et al. Outcomes of extracorporeal membrane oxygenation as a bridge to lung transplantation. Ann Thorac Surg. 2019;107:1456-63. https://doi.org/10.1016/j. athoracsur.2019.01.032.

54. Bain JC, Turner DA, Rehder KJ, et al. Economic outcomes of extracorporeal membrane oxygenation with and without ambulation as a bridge to lung transplantation. Respir Care. 2016;61:1-7. https://doi.org/10.4187/respcare.03729.

55. Hakim AH, Ahmad U, McCurry KR, et al. Contemporary outcomes of extracorporeal membrane oxygenation used as bridge to lung transplantation. Ann Thorac Surg. 2018;106:192-8. https:// doi.org/10.1016/j.athoracsur.2018.02.036.

Publisher's note Springer Nature remains neutral with regard to jurisdictional claims in published maps and institutional affiliations. 